University of Wollongong

Research Online

Australian Institute for Innovative Materials -

Papers

Australian Institute for Innovative Materials

$1-1-2015$

Effects of nanostructure on clean energy: big solutions gained from small features

Jinyan Xiong

University of Wollongong, jx513@uowmail.edu.au

Chao Han

University of Wollongong, ch861@uowmail.edu.au

Zhen Li

University of Wollongong

SX. Dou

University of Wollongong, shi@uow.edu.au

Follow this and additional works at: https://ro.uow.edu.au/aiimpapers

Part of the Engineering Commons, and the Physical Sciences and Mathematics Commons

Research Online is the open access institutional repository for the University of Wollongong. For further information contact the UOW Library: research-pubs@uow.edu.au 


\title{
Effects of nanostructure on clean energy: big solutions gained from small features
}

\author{
Abstract \\ The increasing energy consumption and environmental concerns have driven the development of cost- \\ effective, high-efficiency clean energy. Advanced functional nanomaterials and relevant nanotechnologies \\ are playing a crucial role and showing promise in resolving some energy issues. In this view, we focus on \\ recent advances of functional nanomaterials in clean energy applications, including solar energy \\ conversion, water splitting, photodegradation, electrochemical energy conversion and storage, and \\ thermoelectric conversion, which have attracted considerable interests in the regime of clean energy.
}

\section{Keywords}

small, gained, solutions, big, energy, clean, nanostructure, features, effects

Disciplines

Engineering | Physical Sciences and Mathematics

\section{Publication Details}

Xiong, J., Han, C., Li, Z. \& Dou, S. (2015). Effects of nanostructure on clean energy: big solutions gained from small features. Science Bulletin, 60 (24), 2083-2090. 


\title{
Effects of nanostructure on clean energy: big solutions gained from small features
}

\author{
Jinyan Xiong • Chao Han $\cdot$ Zhen Li $\cdot$ \\ Shixue Dou
}

Received: 20 November 2015 / Accepted: 2 December 2015/Published online: 22 December 2015

(C) Science China Press and Springer-Verlag Berlin Heidelberg 2015

\begin{abstract}
The increasing energy consumption and environmental concerns have driven the development of costeffective, high-efficiency clean energy. Advanced functional nanomaterials and relevant nanotechnologies are playing a crucial role and showing promise in resolving some energy issues. In this view, we focus on recent advances of functional nanomaterials in clean energy applications, including solar energy conversion, water splitting, photodegradation, electrochemical energy conversion and storage, and thermoelectric conversion, which have attracted considerable interests in the regime of clean energy.
\end{abstract}

Keywords Clean energy - Functional nanostructures - Photocatalysis - Solar energy · Electrochemical energy conversion and storage . Thermoelectric conversion

\section{Introduction}

With the explosive growth of population and the threat of global warming, as well as severe pollution problems, human beings have been pushed to develop cost-

\footnotetext{
J. Xiong $\cdot$ C. Han $\cdot$ Z. Li $\cdot$ S. Dou

Institute for Superconducting and Electronic Materials, Australian Institute for Innovative Materials, University of Wollongong, North Wollongong, NSW 2500, Australia

Z. Li (ه)

School of Radiation Medicine and Radiation Protection, Collaborative Innovation Center of Radiation Medicine of Jiangsu Higher Education Institutions, Soochow University, Suzhou 215123, China

e-mail: zhenli@suda.edu.cn
}

effective, high-efficiency solutions to meet the ever increasing demand for clean energy. Advanced functional nanomaterials and relevant nanotechnologies are playing a crucial role in resolving some energy issues. As one of the internationally recognized and highly influential academic journals of China, Chinese Science Bulletin has devoted close attention to state-of-the-art clean energyrelated materials. A special issue on "Advanced Materials for Clean Energy" was published in June 2014 to highlight recent advances in clean energy harvesting, conversion, storage, and utilization through artificial photosynthesis, dye-sensitized solar cells (DSSCs), perovskite solid-state solar cells, electrochemical supercapacitors, rechargeable Li-ion/Na-ion batteries, and thermoelectric materials [1-8]. Here, we summarize the recent promising applications of nanostructures in the field of clean energy (Fig. 1).

\section{Photocatalysis: utilization of solar energy}

Solar energy, as an important inexhaustible source of clean energy, has been investigated for several decades. Although utilizing solar energy includes many aspects, such as solar cells, photocatalytic degradation of pollution, and water splitting, they are all based on the photocatalysis process, which is the acceleration of a photoreaction in the presence of a catalyst and the absorption of solar energy by an adsorbed substrate. The photogenerated catalysis activity (PCA) depends on the ability of the catalyst to create electron-hole pairs, which is able to undergo redox reactions with other species. According to the utilization of the photoelectrons, applications of solar energy based on the photocatalysis process could be divided into the following groups. 


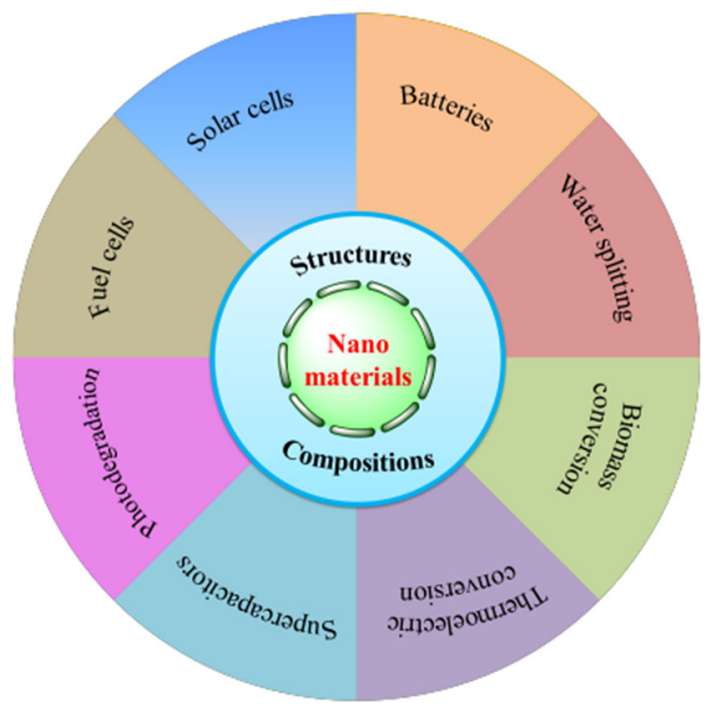

Fig. 1 (Color online) Applications of nanostructures in the field of clean energy

\subsection{Solar energy conversion}

Solar cells are devices that directly convert sunlight into electricity on the basis of the photovoltaic effect, for example meaning that the generated electron-hole pairs are directly used as charge carriers, representing a most promising method for utilization of solar energy. Apart from the expensive traditional $\mathrm{p}-\mathrm{n}$ junction-based silicon solar cells, new prototypes of solar cells have been developed such as sandwich-like dye- or quantum-dotsensitized solar cells, which consist of a counter electrode, electrolyte, and a photoanode [9, 10]. Usually, two basic important processes rule the performance of solar cells: (1) the excitation process, for example generation of photoelectrons by the photoelectrode under irradiation of light and (2) the transport process for the photoelectrons, including the transfer of photoelectrons from inside the photoelectrode to the surface and the transport between the electrolyte and electrodes. Nanostructures not only offer huge surface areas for excitation, but also tune the absorption of light and excitation of photoelectrons via quantum effects [11]. Moreover, the transport of photoelectrons across the interface between the photoelectrode and the electrolyte could be easily tuned by different nanostructures. Hence, the performance of solar cells could be effectively improved by nanostructures with different morphologies and compositions, such as nanowires, mesoporous materials, and monodisperse beads, as well as surface modification through nanotechnology [3, 12, 13]. Hitherto, relatively high power conversion efficiency has been realized for traditional photovoltaic devices; for example, a maximum efficiency of $19.6 \%$ and $20.3 \%$ has been achieved in CdTe quantum-dot solar cells [14] and
$\mathrm{Cu}(\mathrm{In}, \mathrm{Ga}) \mathrm{Se}_{2}$ (CIGS) cells [15], respectively. Despite the high power conversion efficiency, however, their wide applications are strongly limited, either by their expensive fabrication and the rarity of their natural resources or by the high toxicity of some elements. Moreover, the risk of liquid electrolyte leakage is a big issue for long-term operation without degradation.

Another breakthrough in solar cells lies in the usage of organolead halide perovskite $\left(\mathrm{CH}_{3} \mathrm{NH}_{3} \mathrm{PbI}_{3}\right)$ as the sensitizer for high-efficiency solid-state semiconductor-sensitized solar cells [16]. More recently, a high efficiency of $15 \%$ was achieved in $\mathrm{CH}_{3} \mathrm{NH}_{3} \mathrm{PbI}_{3}$-sensitized hybrid solar cells by modifying the deposition of the perovskite light absorber and by increasing the conductivity of the hole transport materials [12]. The conversion occurred within the nanoporous host upon $\mathrm{PbI}_{2}$ and $\mathrm{CH}_{3} \mathrm{NH}_{3} \mathrm{I}$ came into contact, permitting much better control over the perovskite morphology than the previously employed routes [12]. Another rapid rise in solar-to-electric power conversion efficiency to more than $18 \%$ was achieved by incorporation of methylammonium lead bromide $\left(\mathrm{MAPbBr}_{3}\right)$ into formamidinium lead iodide $\left(\mathrm{FAPbI}_{3}\right)$ as the light-harvesting unit by optimizing phase stability, perovskite morphology, hysteresis in $I-V$ characteristics, and overall performance as a function of chemical composition [13]. Zhang and Cai [8] have summarized the progress on organolead halide perovskite-based solar cells. It is highly likely that the conversion efficiency could be further boosted by nanotechnology, which makes it highly promising for large-scale commercialization [17].

\subsection{Generation of hydrogen and oxygen by water splitting}

Hydrogen gas is another highly promising source of clean energy because only water is produced by its burning. In addition, hydrogen possesses extremely low density and high combustion enthalpy, which leads to high energy density. In addition, it can be stored for later use. One of the impediments to its wide application, however, is the high cost of fabrication. Since Fujishima and Honda [18] reported groundbreaking work on the photolytic cleavage of water to $\mathrm{H}_{2}$ and $\mathrm{O}_{2}$ in 1972, the concept of using solar light and a suitable semiconductor catalyst to generate $\mathrm{H}_{2}$ without emitting carbon dioxide via a photoelectrochemical water splitting process or by photovoltaic-driven electrolysis has received tremendous scientific attention [19]. The water splitting reactions only occur when the charge carriers (electrons and holes) generated in the semiconductor from absorption of light can reach the surface during their lifetime and manage to come into contact with protons or water [19]. Thus, the quality of the semiconductor photocatalyst plays a pivotal role in the water splitting. 
Because the absorption of photons from light is strongly correlated with the size and band structure of the semiconductor catalyst, the transport of photoexcited carriers is determined by the crystal type, size, structure, defects, and surface properties of the photocatalyst. To have efficient charge carrier separation, the diffusion length of charge carriers must be longer than the particle size. The chance that the charge carrier reaches the surface of particles increases with the decreasing photocatalyst size; for example, the nanostructure has an important influence on the water splitting [4]. Intensive research has been conducted in the past several decades to develop efficient photoelectrodes, catalysts, and device architectures for solar hydrogen generation [18, 20-23]. The most investigated catalysts are $\mathrm{TiO}_{2}, \mathrm{WO}_{3}$, and $\alpha-\mathrm{Fe}_{2} \mathrm{O}_{3}$ nanostructures [4]. Such nanoeffects have led to 50\%-90\% efficiency gain, according to the literature [24]. For example, bulk single crystal $\alpha-\mathrm{Fe}_{2} \mathrm{O}_{3}$ has very low photocatalytic activity because its paramagnetism shortens the lifetimes and diffusion lengths $(2-20 \mathrm{~nm})$ of photoexcited carriers; in contrast, $\alpha-\mathrm{Fe}_{2} \mathrm{O}_{3}$ nanoparticles with an average size of 10-20 nm exhibit high activity due to their small dimension, which allows the photogenerated carriers diffusing to the electrolyte interface and reacting with water. Furthermore, optimizing the nanostructure of the film could result in absorption of all photons with energies above the band gap [24]. Another example is reported by Chen et al. [1], in which remarkable enhancement of water splitting performance was achieved by coating a pristine $\mathrm{TiO}_{2}$ nanorod film with $\mathrm{Au} @ \mathrm{SiO}_{2}$ core-shell structures, resulting in an increase in the incident photon-to-current conversion efficiency from $31 \%$ to $37 \%$ at $380 \mathrm{~nm}$ at $0.7 \mathrm{~V}$ versus saturated calomel electrode. The enhancement of photoelectrochemical performance could be attributed to the nonconductive $\mathrm{SiO}_{2}$ shell and the spatially nonhomogeneous electric field caused by the metallic surface plasmon resonance of $\mathrm{Au} @ \mathrm{SiO}_{2}$ nanoparticles, which significantly promoted the migration of holes from $\mathrm{TiO}_{2}$ nanorods to electrolyte and hence effectively improved charge carrier separation. Yamada et al. [25] reported that Ni nanoparticles acted as efficient catalysts for photocatalytic hydrogen evolution with 2-phenyl-4-(1-naphthyl) quinolinium ion $\left(\mathrm{QuPh}^{+}\right.$-NA) as the photocatalyst and dihydronicotinamide adenine dinucleotide (NADH) as the sacrificial electron donor. The hydrogen evolution rate of the Ni nanoparticles $(6.6 \mathrm{~nm})$ with hexagonal close-packed (hcp) structure was more than four times higher than the rate of the $\mathrm{Ni}$ nanoparticles with face-centred cubic (fcc) structure of similar size, which was $40 \%$ of that with commercially available $\mathrm{Pt}$ nanoparticles $(2 \mathrm{~nm})$. The high catalytic reactivity of $\mathrm{Ni}$ nanoparticles with smaller size and hcp surface could be ascribed to their high specific surface area compared with the fcc structure. In addition to nickel and iron catalysts used for the electrodes in their electrolyser, a highly efficient and low-cost modular system has been described in which solution-processed solar cells and a catalyst derived from abundant materials were used to achieve a solar energy to hydrogen conversion efficiency of $12.3 \%$. Two $\mathrm{CH}_{3} \mathrm{NH}_{3} \mathrm{PbI}_{3}$-based photovoltaic cells connected in series generated sufficient potential to enable water splitting with a NiFe-layered double hydroxide electrode [26]. However, this system suffered from the lack of stability of the perovskite photovoltaic cells. More recently, another modular system that utilizes concentrated solar power and an electrode based on the earth-abundant material $\mathrm{Ni}$ showed a solar energy to fuel energy conversion efficiency of $22.4 \%$ under various electrolyte conditions [27]. The overall performance of such a system can be optimized by choosing the right electrode material and particle size, as well as the right electrolyser conditions (e.g. electrolyte, operating temperature) [27].

Furthermore, much effort has been devoted to developing robust and efficient catalysts for $\mathrm{H}_{2} \mathrm{O}$ oxidation, to provide the necessary reducing equivalents for the production of solar fuels. Particular attention has been devoted to the design of active artificial water oxidation catalysts. During past decades of research, a great variety of strategies have been explored for the construction of water oxidation catalysts, ranging from molecular complexes based on ruthenium to various kinds of metal oxide materials that are based on three-dimensional (3D) transition metals, such as cobalt and manganese cubanes and spinel phase materials [28]. Gaining a fundamental understanding of structure-activity relationships will certainly offer the key to developing more efficient water oxidation catalysts.

Hydrogenation of nanostructured semiconductors is an effective way to improve their performance in water splitting, and hydrogenated $\mathrm{TiO}_{2}$ and $\mathrm{WO}_{3}$ show significant enhancement in water splitting ability under solar light, because of the increased amount of oxygen vacancies that act as shallow electron donors [4].

\subsection{Degradation of pollutants by photocatalysts}

Semiconductor photocatalysts have demonstrated high efficiency in degrading a wide range of organic pollutants into biodegradable or less toxic organic compounds, as well as inorganic $\mathrm{CO}_{2}, \mathrm{H}_{2} \mathrm{O}, \mathrm{NO}_{3}{ }^{-}, \mathrm{PO}_{4}{ }^{3-}$, and halide ions. As a low-cost route to efficient removal of organic pollutants from waste water, however, the low solar energy conversion efficiency of these inorganic catalysts strongly limits their large-scale application [29]. Now, nanostructuring has become an effective and widely used way to enhance their performance. For example, $\mathrm{TiO}_{2}$ and $\mathrm{ZnO}$, as the most prominent and suitable materials for solar energy harvesting, are being widely studied for 
photodegradation of inorganic and organic pollutants [30]. Their wide band gap limits their light absorption in the ultraviolet (UV) region, however, leading to less use of sunlight. Tian et al. [31] constructed a hybrid nanostructured photocatalyst with enhanced broad spectrum photocatalytic properties by assembling $\mathrm{Bi}_{2} \mathrm{WO}_{6}$ nanosheets on $\mathrm{TiO}_{2}$ nanobelts, which could harness UV, visible, and near-infrared light to decompose organic contaminants in aqueous solution. The enhanced photocatalytic efficiency of the $\mathrm{Bi}_{2} \mathrm{WO}_{6} / \mathrm{TiO}_{2}$ nanobelt heterostructures can be attributed to their heterointegration, oxygen vacancies, and high specific surface area. Ai et al. [32] prepared $\mathrm{N}$-doped $\mathrm{TiO}_{2}$ nanocrystals with exposed $\{001\}$ facets by the sol-gel method and the solvothermal method, respectively, and the as-prepared samples exhibited high visible light photocatalytic performances, as evidenced by decolouration of methylene blue (MB) under visible light irradiation $(\lambda>420 \mathrm{~nm})$, which could be ascribed to their excellent crystallization, strong adsorption ability, and the enhancement of absorbance in the visible light region. The photodegradation rate of Pt-ZnO-reduced graphene oxide (RGO) rods synthesized by a novel Pt-induced electrochemical route with different RGO contents towards aqueous $\mathrm{RhB}$ was markedly improved under UV-visible light irradiation, compared with that of Pt nanoparticle-loaded $\mathrm{ZnO}$. The enhanced photocatalytic activity of Pt-ZnO-RGO towards $\mathrm{RhB}$ could be attributed to the synergistic effects of $\mathrm{ZnO}$ rods and RGO nanosheets, of which RGO nanosheets facilitate the adsorption of $\mathrm{RhB}$ molecules, prevent agglomeration of $\mathrm{ZnO}$ rods, and ensure separation of photoexcited electrons and holes on $\mathrm{ZnO}$ rods [33]. In addition, visible light-driven bismuth-based photocatalysts with various morphology and structures show excellent photocatalytic activities, which could be mainly attributed to the unique hierarchitecture layered structure, large BET surface area, and strong adsorption capacities [34-39]. $\mathrm{Bi}_{2} \mathrm{WO}_{6}$ nanoplates can be also used to oxidize $\mathrm{NH}_{4}{ }^{+} / \mathrm{NH}_{3}$ into $\mathrm{NO}_{3}{ }^{-}$and a trace of $\mathrm{NO}_{2}{ }^{-}$in an alkaline solution under fluorescent light irradiation, and the transfer of photogenerated holes could play a crucial role in the photocatalytic oxidation process of the ammonia [40]. Our group [41] also prepared a novel class of onedimensional (1D) plasmonic $\mathrm{Ag} @ \mathrm{Cu}_{2} \mathrm{O}$ core-shell heteronanowires by a facile solution process at room temperature, which exhibited much higher photocatalytic activity towards degradation of organic contaminants than $\mathrm{Ag} @ \mathrm{Cu}_{2} \mathrm{O}$ core-shell nanoparticles or pure $\mathrm{Cu}_{2} \mathrm{O}$ nanospheres under solar light irradiation. The drastic enhancement in photocatalytic activity could be attributed to the surface plasmon resonance, the electron sink effect of the Ag nanowire cores, and the unique 1D core-shell nanostructure.

\section{Electrochemical energy conversion and storage}

Lithium-ion batteries, usually based on insertion-extraction of lithium ions, are primarily used for energy storage [7]. Compared with other batteries, they show relatively high energy density and emit low pollution to the environment. Recent progress on these batteries has made electrically powered vehicles realistic alternatives, which could significantly reduce the pollution due to waste exhaust from petrol vehicles. Nevertheless, the two biggest challenges for realizing electrically powered vehicles lie in how to realize: (1) fast charge and discharge with good retention of capacity and (2) good cycling stability for a long service life to reduce the cost. The performance of an energy storage device is primarily dependent on the properties of the electrode materials. The charge/discharge speed of the lithium-ion batteries is mainly controlled via the electrochemical reaction speed and the ion diffusion speed, and the cycling stability is related to the volume changes before and after charge/discharge. It has been both theoretically and experimentally proved that nanostructures could solve these problems [4, 6, 7, 42-44]. This is because the high surface area of nanostructures offers plentiful reaction sites for the electrochemical reactions, and the diffusion paths of charge carriers (or ions) could also be significantly shortened by nanoscale electrode materials. Moreover, pulverization of the electrode materials can be significantly improved by nanostructuring.

For example, lithium-ion batteries employing $\mathrm{Cu}_{2-x} \mathrm{Te}$ nanosheets as anode showed superior cycling stability up to 5,000 cycles with a charge/discharge rate of $2 \mathrm{C}$ and a capacity of $100 \mathrm{mAh} / \mathrm{g}$, which was attributed to their variable compositions and structures, better electronic contact, and small volume expansion/shrink during charge and discharge [45]. Hybrid carbon- $\mathrm{Li}_{4} \mathrm{Ti}_{5} \mathrm{O}_{12}$ nanocomposites with diameters of a few micrometres, composed of numerous nanosheets, exhibited a reversible charge-discharge capacity of $\sim 169 \mathrm{mAh} / \mathrm{g}$ ( $\sim 97 \%$ of its theoretical capacity, $175 \mathrm{mAh} / \mathrm{g}$ ) at the $10 \mathrm{C}$ rate, superior to pure $\mathrm{n}-\mathrm{Li}_{4} \mathrm{Ti}_{5} \mathrm{O}_{12} \quad(\sim 106 \mathrm{mAh} / \mathrm{g})$, porous $\mathrm{Li}_{4} \mathrm{Ti}_{5} \mathrm{O}_{12} / \mathrm{TiO}_{2}$ $\left(103.7 \mathrm{mAh} / \mathrm{g}\right.$ ) nanostructures, and commercial $\mathrm{Li}_{4} \mathrm{Ti}_{5} \mathrm{O}_{12}$ powders $(\sim 85 \mathrm{mAh} / \mathrm{g})$. This excellent performance is attributed to the good conductivity, large surface area, and stable structure of such micro-nanostructures, which could be explored as promising anode materials for lithium-ion batteries [6]. Doping graphene with nitrogen, boron, phosphorus, or their composites is an effective way to increase the specific energy storage capacity and rate performance, both of which are critically important in designing effective energy storage systems for large-scale applications, including renewable energy [7].

Sodium-ion $\left(\mathrm{Na}^{+}\right)$batteries have recently attracted increased attention for electrical energy storage owing to 
the natural abundance and low cost of sodium, which could enable sodium-ion batteries to act as a low-cost substitute for lithium-ion batteries. Nanocomposites with ultra-small magnetite $\left(\mathrm{Fe}_{3} \mathrm{O}_{4}\right)$ nanoparticles (about $3 \mathrm{~nm}$ ) uniformly anchored on the surfaces of RGO nanosheets were synthesized by a novel single-step high-temperature coprecipitation approach for use as anodes in sodium-ion batteries. The electrodes showed superior cycling performance with a reversible Na-storage capacity of $204 \mathrm{mAh} / \mathrm{g}$ and outstanding cycling stability (i.e., $98 \%$ capacity retained after 200 cycles) due to the synergetic effect of the uniform distribution of the ultra-small $\mathrm{Fe}_{3} \mathrm{O}_{4}$ nanoparticles $(3 \mathrm{~nm})$ and the buffering role of the highly conductive RGO nanosheets [46]. Mesoporous carbon with 9.5-nm pores synthesized by packing and carbonization of resorcinol and formaldehyde nanospheres $(50 \mathrm{~nm})$, exhibited a high initial capacity $(410 \mathrm{mAh} / \mathrm{g})$ and good capacity retention (125 mAh/g after 100 cycles) as anode for sodium-ion batteries. The improved efficiency (>97\%) and cycling stability could be attributed to their high surface area, the large mesopores and micropores in the carbon spheres, and the superior connectivity and conductivity of the mesoporous network [42]. Such results suggest the possibility of constructing low-cost sodium-ion batteries by using mesoporous carbon with large nanopores and RGObased nanocomposites.

Besides sodium and lithium-ion batteries, nanostructuring has also proved to be an effective way to enhance the performance of other energy storage systems, such as supercapacitors [4, 47, 48], Li-S batteries [49], Li-air batteries [50], microbial fuel cells [51], and solid oxide fuel cells [52].

\section{Thermoelectric conversion}

Thermoelectric technology based on the Seebeck effect, which was discovered in 1836 by Thomas Johann Seebeck, can convert heat into electricity directly via a flow of charge carriers from the hot side to the cold side in semiconductors [53]. It has distinct advantages, such as reliability, silent operation without mechanical movement, simplicity, and zero emissions [2]. Although this technique has many merits and a long history, only niche applications of this technology have appeared due to its extremely low conversion efficiency (typically $<6 \%$ ), which is related to the low value of the dimensionless figure of merit $(Z T)$. The difficulty in increasing $Z T$ lies in the fact that it is very difficult to simultaneously optimize the three "interlocked" factors: high electrical conductivity, high Seebeck coefficient, and low thermal conductivity. Hence, $Z T$ values have been limited to below 1 until Hicks and Dresselhaus [54, 55] theoretically proved that low-dimensional materials could have higher ZT than their bulk analogues, due both to their lower thermal conductivity and to quantum confinement effects. The highest known $Z T$ value $(Z T=3.0$ at $550 \mathrm{~K}$ ) was achieved in Bi-doped n-type $\mathrm{PbSeTe} / \mathrm{PbTe}$ quantum-dot superlattices (QDSLs) grown by molecular beam epitaxy (MBE) [56]. Han et al. [2] summarized the recent progress on different kinds of thermoelectric materials in their comprehensive review and pointed out that nanostructuring was the most important strategy for enhancing $Z T$ values, not only because nanostructuring could effectively decrease thermal conductivity, but also because it could cause an energy filtering effect that increases the Seebeck coefficient. Later, they proposed a low-cost surfactant-free route to the synthesis of different nanostructured thermoelectric materials, and obvious enhancement of $Z T$ was achieved [57-60]. In particular, the pronounced enhancement in $Z T$ of some metal chalcogenide nanostructures was achieved due to the presence of nanograins or nanopores, which can effectively decrease the thermal conductivity [57].

\section{Others}

In addition to the above-mentioned clean energy applications, there are some other systems for clean energy applications. Advanced materials and nanotechnology related to clean coal and fossil fuels, biofuels and biomass conversion, biosystem, and bioinspired system for energy conversion, piezoelectric conversion, and $\mathrm{CO}_{2}$ capture, storage, and utilization, as well as hydrogen storage, have been researched intensively for clean energy applications in recent decades [48, 61-69]. For example, synthesis of methane $\left(\mathrm{CH}_{4}\right)$ from syngas $\left(\mathrm{CO}+\mathrm{H}_{2}\right)$ has been applied for the removal of unwanted $\mathrm{CO}$ for ammonia production, fuel cells, and others, as well as the production of natural gas derives [70]. Yan et al. [70] prepared $\mathrm{Ni} / \mathrm{SiO}_{2}$ catalysts for $\mathrm{CO}$ methanation by dielectric-barrier discharge (DBD) plasma decomposition, and the resultant catalyst exhibited significantly improved activity with enhanced stability due to its smaller particle size with higher dispersion, less defects, and enhanced metal-support $(\mathrm{Ni}-$ $\mathrm{SiO}_{2}$ ) interactions. Gong et al. [71] developed the simultaneous saccharification and enhanced lipid production (SSELP) process for efficient conversion of lignocellulosic materials into microbial lipids with higher lipid coefficient than those obtained by using the conventional process. Specifically, Cryptococcus curvatus cells were cultivated in corn stover containing hydrolytic enzymes. When cellulose was loaded at $32.3 \mathrm{~g} / \mathrm{L}$, cellulose conversion, cell mass, lipid content, and lipid coefficient reached $98.5 \%, 12.4 \mathrm{~g} / \mathrm{L}, 59.9 \%$, and $204 \mathrm{mg} / \mathrm{g}$, respectively. The SSELP process greatly reduced time 
and costs and appeared promising for the production of fatty acid-derived products from lignocellulosic biomass.

Liu et al. [61] fabricated a hybrid system of semiconducting nanowires and bacteria that mimics the natural photosynthetic process by using solar energy to synthesize carbohydrates from $\mathrm{CO}_{2}$ and $\mathrm{H}_{2} \mathrm{O}$. The high-surface-area silicon nanowire array harvests light energy to provide reducing equivalents to the anaerobic bacterium, Sporomusa ovata, for the photoelectrochemical production of acetic acid under aerobic conditions $\left(21 \% \mathrm{O}_{2}\right)$ with low over potential ( $\eta<200 \mathrm{mV}$ ), high Faradaic efficiency (up to $90 \%$ ), and long-term stability (up to $200 \mathrm{~h}$ ). The resulting acetate $(\sim 6 \mathrm{~g} / \mathrm{L})$ could be activated to acetyl coenzyme A (acetyl-CoA) by genetically engineered Escherichia coli and used as a building block for a variety of value-added chemicals, such as $n$-butanol, polyhydroxybutyrate (PHB) polymer, and three different isoprenoid natural products [61]. Zhang et al. [72] prepared a combined system ammonia borane@polypyrrole (AB@PPy), which was able to release $\mathrm{H}_{2}$ at temperatures as low as $48^{\circ}$, and up to $15.3 \mathrm{wt} \%$ pure hydrogen could be released below $150{ }^{\circ} \mathrm{C}$. The improvement was ascribed to the synergistic effects of nanoconfinement and N-catalysis, which suggested that the AB@PPy composite was a safe material for potential hydrogen storage.

Nanostructured $\mathrm{ZnO}$ is reported to be an ideal piezoelectric material with significant improvements in energy harvesting performance $[69,73]$. For example, piezoelectric $\mathrm{ZnO}$ nanorods grown on a flexible substrate are combined with the p-type semiconducting polymer PEDOT: PSS to produce a $\mathrm{p}-\mathrm{n}$ junction device that successfully demonstrated improved kinetic-to-electrical energy conversion. Both the voltage and current output of the devices were measured to be in the range of $10 \mathrm{mV}$ and $10 \mu \mathrm{A} /$ $\mathrm{cm}^{2}$, respectively. Combining these figures for the best device gave a maximum possible power density of $0.4 \mathrm{~mW} / \mathrm{cm}^{3}[73]$.

\section{Summary and outlook}

It is easy to notice that most of the progress in clean energy is related to nanotechnology. Chinese scientists working inside and outside domestic institutes have achieved fruitful outcomes in advanced clean energy materials in recent years. The positive roles of nanostructures in clean energy research are well accepted, and there are still some fundamental issues debated in real applications. For example, high surface area leads to self-discharge, poor cycling, and calendar life of batteries and their inferior packing of nanoparticles also leads to lower volumetric energy densities. Small particle size of photocatalysts results in their poor cycling performance due to their instability. Poor stability of thermoelectric nanostructures also leads to possible crush during sintering into highly dense pellets at high temperature or high pressure, and low thermoelectric conversion efficiency.

The future efforts in nanostructures for clean energy could be considered as follows. First of all, the oriented design and synthesis of catalysts to improve their selectivity, conversion efficiency, and stability have always been a challenge in the field of catalysis research. In particular, the design and selection of catalysts play key roles in many areas of clean energy, such as photocatalysis, environmental catalysis, the oxygen reduction reaction, clean coal, and biomass conversion. Secondly, the synthesis of highly tunable and complex porous structures and 3D hierarchical nanostructures with improved accessibility, larger surface area, and better dispersion of the active species has been widely used in environmental and energy applications, such as solar cells, lithium-ion batteries, water treatment, carbon dioxide and hydrogen storage, and thermoelectric devices. At present, the biggest challenge is to select the ideal functional materials with improved conversion efficiency, catalytic efficiency, gas-stripping absorption efficiency, etc. Multifunctional nanomaterials are often required in order to create the desired synergetic effects. Finally, the large-scale commercialization of nanomaterials and devices still remains a big challenge around the world. Coincident with the giant economic development occurring in China, revolutionary advances in nanotechnology and a deeper mechanistic understanding of the properties of materials, from combining progressively improved research conditions and more significant achievements generated in domestic laboratories and industries in China, are very much expected.

Acknowledgments Zhen Li acknowledges support from the Australian Research Council (ARC) through the Discovery Projects DP130102699 and DP130102274. Shixue Dou is grateful for support from ARC through the Linkage Project LP120200289. The authors would like to thank the support from the Institute for Superconducting and Electronic Materials (ISEM), the Priority Academic Program Development of Jiangsu Higher Education Institutions (PAPD), Jiangsu Provincial Key Laboratory of Radiation Medicine and Protection, and also thank Dr. Tania Silver for polishing the manuscript.

Conflict of interest The authors declare that they have no conflict of interest.

\section{References}

1. Chen J, Yu M, Wang Y et al (2014) Au@ $\mathrm{SiO}_{2}$ core/shell nanoparticle-decorated $\mathrm{TiO}_{2}$ nanorod arrays for enhanced photoelectrochemical water splitting. Chin Sci Bull 59:2191-2198

2. Han C, Li Z, Dou S (2014) Recent progress in thermoelectric materials. Chin Sci Bull 59:2073-2091 
3. Li Z, Zhou Y, Sun $\mathrm{R}$ et al (2014) Nanostructured $\mathrm{SnO}_{2}$ photoanode-based dye-sensitized solar cells. Chin Sci Bull 59: 2122-2134

4. Qiu J, Dawood J, Zhang S (2014) Hydrogenation of nanostructured semiconductors for energy conversion and storage. Chin Sci Bull 59:2144-2161

5. Wang Z, Wu Y, Wang L et al (2014) Polarization behavior of microbial fuel cells under stack operation. Chin Sci Bull 59: 2214-2220

6. Wen R, Yue J, Ma Z et al (2014) Synthesis of $\mathrm{Li}_{4} \mathrm{Ti}_{5} \mathrm{O}_{12}$ nanostructural anode materials with high charge-discharge capability. Chin Sci Bull 59:2162-2174

7. Wen Y, Huang C, Wang L et al (2014) Heteroatom-doped graphene for electrochemical energy storage. Chin Sci Bull 59:2102-2121

8. Zhang WH, Cai B (2014) Organolead halide perovskites: a family of promising semiconductor materials for solar cells. Chin Sci Bull 59:2092-2101

9. Chen XQ, Li Z, Bai Y et al (2015) Room-temperature synthesis of $\mathrm{Cu}_{2-x} \mathrm{E}(\mathrm{E}=\mathrm{S}, \mathrm{Se})$ nanotubes with hierarchical architecture as high-performance counter electrodes of quantum-dot-sensitized solar cells. Chem Eur J 21:1055-1063

10. Chen XQ, Bai Y, Sun Q et al (2015) Ambient synthesis of onedimensional/two-dimensional CuAgSe ternary nanotubes as highperformance counter electrodes of quantum-dot-sensitized solar cells. ChemPlusChem. doi:10.1002/cplu.201500466R201500461

11. Beard MC, Luther JM, Nozik AJ (2014) The promise and challenge of nanostructured solar cells. Nat Nanotechnol 9:951-954

12. Burschka J, Pellet N, Moon SJ et al (2013) Sequential deposition as a route to high-performance perovskite-sensitized solar cells. Nature 499:316-319

13. Jeon NJ, Noh JH, Yang WS et al (2015) Compositional engineering of perovskite materials for high-performance solar cells. Nature 517:476-480

14. Green MA, Emery K, Hishikawa Y et al (2013) Solar cell efficiency tables (version 42). Prog Photovolt 21:827-837

15. Jackson P, Hariskos D, Lotter E et al (2011) New world record efficiency for $\mathrm{Cu}(\mathrm{In}, \mathrm{Ga}) \mathrm{Se}_{2}$ thin-film solar cells beyond $20 \%$. Prog Photovolt 19:894-897

16. Kim HS, Lee CR, Im JH et al (2012) Lead iodide perovskite sensitized all-solid-state submicron thin film mesoscopic solar cell with efficiency exceeding $9 \%$. Sci Rep 2:591

17. Stranks SD, Snaith HJ (2015) Metal-halide perovskites for photovoltaic and light-emitting devices. Nat Nanotechnol 10: 391-402

18. Fujishima A, Honda K (1972) Electrochemical photolysis of water at a semiconductor electrode. Nature 238:37-38

19. Navarro Yerga RM, Álvarez Galván MC, del Valle F et al (2009) Water splitting on semiconductor catalysts under visible-light irradiation. ChemSusChem 2:471-485

20. Walter MG, Warren EL, McKone JR et al (2010) Solar water splitting cells. Chem Rev 110:6446-6473

21. Reece SY, Hamel JA, Sung K et al (2011) Wireless solar water splitting using silicon-based semiconductors and earth-abundant catalysts. Science 334:645-648

22. Brillet J, Yum JH, Cornuz M et al (2012) Highly efficient water splitting by a dual-absorber tandem cell. Nat Photon 6:824-828

23. Pinaud BA, Benck JD, Seitz LC et al (2013) Technical and economic feasibility of centralized facilities for solar hydrogen production via photocatalysis and photoelectrochemistry. Energy Environ Sci 6:1983-2002

24. Osterloh FE, Parkinson BA (2011) Recent developments in solar water-splitting photocatalysis. MRS Bull 36:17-22

25. Yamada Y, Miyahigashi T, Kotani H et al (2012) Photocatalytic hydrogen evolution with $\mathrm{Ni}$ nanoparticles by using 2-phenyl-4(1-naphthyl)quinolinium ion as a photocatalyst. Energy Environ Sci 5:6111-6118
26. Luo J, Im JH, Mayer MT et al (2014) Water photolysis at $12.3 \%$ efficiency via perovskite photovoltaics and earth-abundant catalysts. Science 345:1593-1596

27. Bonke SA, Wiechen M, MacFarlane DR et al (2015) Renewable fuels from concentrated solar power: towards practical artificial photosynthesis. Energy Environ Sci 8:2791-2796

28. Kärkäs MD, Verho O, Johnston EV et al (2014) Artificial photosynthesis: molecular systems for catalytic water oxidation. Chem Rev 114:11863-12001

29. Wang CC, Li JR, Lv XL et al (2014) Photocatalytic organic pollutants degradation in metal-organic frameworks. Energy Environ Sci 7:2831-2867

30. Chen C, Ma W, Zhao J (2010) Semiconductor-mediated photodegradation of pollutants under visible-light irradiation. Chem Soc Rev 39:4206-4219

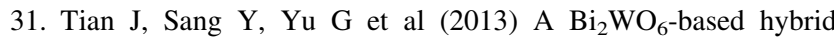
photocatalyst with broad spectrum photocatalytic properties under UV, visible, and near-infrared irradiation. Adv Mater 25:5075-5080

32. Ai H, Shi J, Chen J et al (2014) The preparation of nitrogen-doped $\mathrm{TiO}_{2}$ nanocrystals with exposed 001 facets and their visible-light photocatalytic performances. Chin Sci Bull 59:2199-2207

33. Wang X, Yao X (2014) Pt-induced electrochemical growth of $\mathrm{ZnO}$ rods onto reduced graphene oxide for enhanced photodegradation performance. Chin Sci Bull 59:2208-2213

34. Xiong J, Cheng G, Li G et al (2011) Well-crystallized square-like 2D BiOCl nanoplates: mannitol-assisted hydrothermal synthesis and improved visible-light-driven photocatalytic performance. RSC Adv 1:1542-1553

35. Xiong J, Cheng G, Qin F et al (2013) Tunable BiOCl hierarchical nanostructures for high-efficient photocatalysis under visible light irradiation. Chem Eng J 220:228-236

36. Xiong J, Jiao Z, Lu G et al (2013) Facile and rapid oxidation fabrication of $\mathrm{BiOCl}$ hierarchical nanostructures with enhanced photocatalytic properties. Chem Eur J 19:9472-9475

37. Cheng G, Xiong J, Stadler FJ (2013) Facile template-free and fast refluxing synthesis of $3 \mathrm{D}$ desertrose-like $\mathrm{BiOCl}$ nanoarchitectures with superior photocatalytic activity. New J Chem 37:3207-3213

38. Xiong J, Cheng G, Lu Z et al (2011) BiOCOOH hierarchical nanostructures: shape-controlled solvothermal synthesis and photocatalytic degradation performances. CrystEngComm 13: $2381-2390$

39. Xiong J, Dong Q, Wang T et al (2014) Direct conversion of Bi nanospheres into 3D flower-like $\mathrm{BiOBr}$ nanoarchitectures with enhanced photocatalytic properties. RSC Adv 4:583-586

40. Zhang L, Wang W, Sun S (2014) Photocatalytic oxidation of ammonia by $\mathrm{Bi}_{2} \mathrm{WO}_{6}$ nanoplates using fluorescent light. Chin Sci Bull 59:2181-2185

41. Xiong J, Li Z, Chen J et al (2014) Facile synthesis of highly efficient one-dimensional plasmonic photocatalysts through $\mathrm{Ag} @ \mathrm{Cu}_{2} \mathrm{O}$ core-shell heteronanowires. ACS Appl Mater Interfaces 6:15716-15725

42. Liu J, Liu H, Yang T et al (2014) Mesoporous carbon with large pores as anode for Na-ion batteries. Chin Sci Bull 59:2186-2190

43. Singh $\mathrm{P}$, Shiva $\mathrm{K}$, Celio $\mathrm{H}$ et al (2015) Eldfellite, $\mathrm{NaFe}\left(\mathrm{SO}_{4}\right)_{2}$ : an intercalation cathode host for low-cost Na-ion batteries. Energy Environ Sci 8:3000-3005

44. Wang J, Eng C, Chen-Wiegart YK et al (2015) Probing threedimensional sodiation-desodiation equilibrium in sodium-ion batteries by in situ hard X-ray nanotomography. Nat Commun 6:7496

45. Han C, Li Z, Li WJ et al (2014) Controlled synthesis of copper telluride nanostructures for long-cycling anodes in lithium ion batteries. J Mater Chem A 2:11683-11690

46. Zhang S, Li W, Tan B et al (2015) One-pot synthesis of ultrasmall magnetite nanoparticles on the surface of reduced graphene 
oxide nanosheets as anodes for sodium-ion batteries. J Mater Chem A 3:4793-4798

47. Wang G, Zhang L, Zhang J (2012) A review of electrode materials for electrochemical supercapacitors. Chem Soc Rev 41:797-828

48. Linares N, Silvestre-Albero AM, Serrano E et al (2014) Mesoporous materials for clean energy technologies. Chem Soc Rev 43:7681-7717

49. Manthiram A, Fu Y, Chung $\mathrm{SH}$ et al (2014) Rechargeable lithium-sulfur batteries. Chem Rev 114:11751-11787

50. Balaish M, Kraytsberg A, Ein-Eli Y (2014) A critical review on lithium-air battery electrolytes. Phys Chem Chem Phys 16:2801-2822

51. Wang H, Park JD, Ren ZJ (2015) Practical energy harvesting for microbial fuel cells: a review. Environ Sci Technol 49:3267-3277

52. Kilner JA, Burriel M (2014) Materials for intermediate-temperature solid-oxide fuel cells. Ann Rev Mater Res 44:365-393

53. Li Z, Sun Q, Yao XD et al (2012) Semiconductor nanowires for thermoelectrics. J Mater Chem 22:22821-22831

54. Hicks LD, Dresselhaus MS (1993) Thermoelectric figure of merit of a one-dimensional conductor. Phys Rev B 47:16631-16634

55. Hicks LD, Dresselhaus MS (1993) Effect of quantum-well structures on the thermoelectric figure of merit. Phys Rev B 47:12727-12731

56. Harman TC, Walsh MP, laforge BE et al (2005) Nanostructured thermoelectric materials. J Electron Mater 34:L19-L22

57. Han C, Li Z, Lu GQ et al (2015) Robust scalable synthesis of surfactant-free thermoelectric metal chalcogenide nanostructures. Nano Energy 15:193-204

58. Han C, Sun Q, Cheng ZX et al (2014) ambient scalable synthesis of surfactant-free thermoelectric $\mathrm{CuAgSe}$ nanoparticles with reversible metallic-n-p conductivity transition. J Am Chem Soc 136:17626-17633

59. Chen XQ, Li Z, Dou SX (2015) Ambient facile synthesis of gramscale copper selenide nanostructures from commercial copper and selenium powder. ACS Appl Mater Interfaces 7:13295-13302

60. Chen X, Li Z, Yang J et al (2015) Aqueous preparation of surfactant-free copper selenide nanowires. J Colloid Interface Sci 442:140-146
61. Liu C, Gallagher JJ, Sakimoto KK et al (2015) Nanowire-bacteria hybrids for unassisted solar carbon dioxide fixation to valueadded chemicals. Nano Lett 15:3634-3639

62. Cuéllar-Franca RM, Azapagic A (2015) Carbon capture, storage and utilisation technologies: a critical analysis and comparison of their life cycle environmental impacts. $\mathrm{J} \mathrm{CO}_{2}$ Util 9:82-102

63. Li L, Zhao N, Wei W et al (2013) A review of research progress on $\mathrm{CO}_{2}$ capture, storage, and utilization in Chinese Academy of Sciences. Fuel 108:112-130

64. Jena P (2011) Materials for hydrogen storage: past, present, and future. J Phys Chem Lett 2:206-211

65. Durbin DJ, Malardier-Jugroot C (2013) Review of hydrogen storage techniques for on board vehicle applications. Int $\mathrm{J}$ Hydrogen Energy 38:14595-14617

66. Akia M, Yazdani F, Motaee E et al (2014) A review on conversion of biomass to biofuel by nanocatalysts. Biofuel Res J $1: 16-25$

67. Chen WH, Lin BJ, Huang MY et al (2015) Thermochemical conversion of microalgal biomass into biofuels: a review. Bioresour Technol 184:314-327

68. Zheng YJ, Chen SY, Lin Y et al (2013) Bio-inspired optimization of sustainable energy systems: a review. Math Probl Eng 2013:12

69. Bowen CR, Kim HA, Weaver PM et al (2014) Piezoelectric and ferroelectric materials and structures for energy harvesting applications. Energy Environ Sci 7:25-44

70. Yan X, Liu Y, Zhao B et al (2013) Methanation over $\mathrm{Ni} / \mathrm{SiO}_{2}$ : effect of the catalyst preparation methodologies. Int J Hydrogen Energy 38:2283-2291

71. Gong Z, Shen H, Wang Q et al (2013) Efficient conversion of biomass into lipids by using the simultaneous saccharification and enhanced lipid production process. Biotechnol Biofuels 6:36

72. Zhang L, Xia G, Ge Y et al (2015) Ammonia borane confined by nitrogen-containing carbon nanotubes: enhanced dehydrogenation properties originating from synergetic catalysis and nanoconfinement. J Mater Chem A 3:20494-20499

73. Briscoe J, Stewart M, Vopson M et al (2012) Nanostructured p-n junctions for kinetic-to-electrical energy conversion. Adv Energy Mater 2:1261-1268 